\title{
Summaries and Biographies
}

\section{Ari Páll Kristinsson}

Ari Páll Kristinsson holds a Doctoral degree in Icelandic Linguistics. He is an experienced language consultant, among other things at the Icelandic State Broadcasting Service. He was Director of The Icelandic Language Institute in 1996-2006. His current position is Research Professor and Head of Language Planning Department at The Ârni Magnússon Institute for Icelandic Studies.

\section{Icelandic plain language as a research field}

The paper discusses Icelandic plain language as a research field. The conclusion is that until recently, Icelandic linguists did not find it worthwhile to prioritize research into plain language. The author suggests that this lack of interest can be explained by the ideology that plain language use is inherently entailed by Iceland's prevailing lexical purism, deep-rooted respect for 'Saga style' concise sentences, traditional grammar, and ancient idioms. Consequently, the general perception has been that there is no particular need for plain language efforts. Recent Icelandic language legislation (2011) challenges this traditional indifference towards plain language research, as the law stipulates that the language used in activities of government and municipalities shall be "good", plain and clear (Art. 10). This act can motivate future researchers to attend to Icelandic plain language. The author emphasizes the value of language discourses as material for such research.

\section{Anja Flebbe}

Anja Flebbe holds a Master of Arts degree in corporate communication, specializing in online communications from the Aarhus School of Business, University of Aarhus. Since 2011, she has worked with digital communications at the Municipality of Horsens, including projects on the use, support and promotion of digital self service, and citizen involvement through social media. 
The Municipality of Horsens won the special award for the promotion of digital channels in the competition for public authorities, Top of the Web (Bedst på Nettet) 2012.

\section{Citizens and municipality meeting digitally}

Citizens expect digital communication with public authorities to be as smooth as other online services. However, it is not easier to claim benefits and services only because it is done digitally. For municipalities and other public authorities, it is expensive when the citizens makes phone calls or show up at city hall, rather than using the online channels - and the municipalities experience budget reductions because of the savings digitization is meant to generate.

The Municipality of Horsens have experienced success by, inspired by e-commerce, seeing digital self service as a product to be sold. The approach changes the rhetoric and language in the digital communication between citizen and public authority, and emphasizes the need for a holistic approach to digital self service. Different target groups present different challenges: the older generation may have difficulties in the digital interactions, whereas the younger age groups may have a hard time understanding certain key concepts in the language used by the municipality and other authorities.

\section{Iris Furu}

Iris Alice Vigerust Furu has an MA in Rhetoric and Communication and works as an advisor in The Norwegian Non-fiction Writers and Translators Association (NFF). She is also a columnist and a freelance text consultant.

\section{A wall of text}

Iris Furu presents findings from her master's thesis in Rhetoric and Communication in which she studies the language used in different kinds of informing texts and forms from NAV, the Norwegian Labour and Welfare Administration.

Expecting parents in Norway can apply for parental benefits from NAV by filling out a specific form. What makes these forms the way they are, and do Norwegian parents understand how to fill them out?

Through qualitative interviews with both NAV employees and Norwegian citizens, Furu has provided a closer look into the communication processes between the state and the citizens in Norway. By looking at the statements from both sender and recipient she has been able to show what happens when the communication between the system and the user is successful - and when it fails. 


\section{Kaj Hoffrén}

Kaj Hoffrén is Senior Adviser at the Steering and Development Unit for Personal Taxation at the Tax Administration, and has worked for the Finnish tax authorities since 1989. He is currently working with the prepayment of tax, and has been involved with developing the Tax Card Online service since its launch in 2006. Tax Card Online was the first interactive web service for private customers implemented by the Tax Administration.

\section{Get your tax card online - one example of how the Tax Administration is develop- ing electronic services}

Tax card online is an e-service offered by the Finnish Tax Administration to anyone who needs to change their tax card in the course of the year. Prior to implementation, the usability of the service was tested with the help of a company specializing in Internet services. An additional usability test was made prior to its launch, where a group of customers were invited to test the service and give their feedback on it.

In order that the service should be perceived as easy and user-friendly, the language and instructions have been made as simple as possible. The Tax Administration hired language advisors to write the texts. Translations were done by professional translators.

Going forward, customer response will play a big part in the development of the service. There is an online feedback form available to users. Customer response regarding incoming requests for support is also followed up. Usability is examined approximately every two years, looking specifically at the age of the customers, how familiar they are with the service and which parts of the service have been considered problematic.

\section{Anne Kjærgaard}

Anne Kjærgaard is a scientific member of staff at Dansk Sprognævn and holds a postdoc grant since 1 January 2012. She is interested in the written communication between public-sector authorities and private citizens, the language policies of organizations, preconditions for language advice in the public sector and norms of communication between the public sector and the citizens.

\section{Do citizens understand what SKAT is writing? Recipient analyses of letters re- ceived from the Danish tax authority}

The plain language tradition in Denmark is based on certain specific assumptions of what makes public-sector texts more easily understandable and approachable to the recipients, and these assumptions are often crystallized into very concrete advice for writing good texts (for instance, "use fewer passives", "avoid verbalizing nouns" and 
"place the conclusion first"). However, empirical evidence for such instructions is actually very limited.

In the presentation, I outline my current postdoc project which aims to shed light on whether the effort to revise texts in the public sector is on target. The Danish tax administration, SKAT, has worked for several years on revising its texts and has received recognition for its efforts: for instance, it was awarded the Danish business language prize (Ehrvervssprogprisen) for one of its letters. The survey is based on three different but authentic versions of the same letter, in other words, all versions of the letter are written by employees of SKAT. The purpose of the survey is to examine whether there is a difference regarding how, and to what extent, equal groups of readers understand the three versions of the letter.

The focus of the presentation will be on presenting the themes and possible problems of the project, and on introducing and discussing methods as well as the preliminary results.

Summary of Conference Presentation.

\section{Lena Lind Palicki}

Lena Lind Palicki is a language advisor in Swedish and works at The Swedish Language Council in Sweden. She has a degree in language consultancy and a $\mathrm{PhD}$ in the Swedish language. Her primary research interests are the language used by the authorities as well as language and gender, and her doctoral thesis of 2010 focused on the language used by The National Agency for Social Insurance when addressing parents. She is currently working with language planning and a research project on plain language as policy and in practice.

\section{Plain language as policy and in practice - what do we know about plain language and what do we need to know?}

The plain language work in Sweden is fundamentally a political language planning project. Plain language is well established nowadays, with an elaborate practice and traditions dating back to the 1950s. However, it still seems difficult to really pin down what plain language is. What is plain language at the policy level, and what does it become once it is put into practice? Words used when arguing for plain language include democracy, efficiency and the safeguarding of legal rights. But what happens when such a language policy project is to be implemented? When it becomes necessary to take into account local resources, aims and motives? Plain language is implemented in different ways and at several different levels. In my presentation I focus on plain language policy documents as well as the practical implementation: plain 
language education, and the plain language texts of commercial language advisory companies.

\section{Sissel C. Motzfeldt}

Sissel C. Motzfeldt is a senior adviser at the Agency for Public Management and eGovernment, which aims to strengthen the government's work in renewing the Norwegian public sector. She was the project manager for the project "Plain Language in Norway's Civil Service" from 2009 and until the summer of 2011, but is now the project manager for the Plain Legal project aiming at improving the language in laws and regulations. She has more than 35 years of experience from the Norwegian Central Government and has played a major role in the development of the Central Government Communication Policy. She has worked with user involvement and strategy development for ministries and agencies in the field of communication.

\section{How to improve the language in laws and regulations? What will challenge us?}

In the Plain Legal project we started our work by establishing a knowledge base. We conducted two surveys-one directed at the general public and the other at civil servants from ministries and agencies. The surveyors found that 54 percent of the public said they had read a law or regulation in the previous year concerning work, health, welfare, housing or the economy. This showed that clear legislation was important for the general public too. The survey directed at civil servants showed that linguists were seldom used in the legislative process and that draft laws were almost never user-tested. Our knowledge base has proved very useful in our work, and has helped us work systematically in the right direction. We are on our way, but we still have a long way to go. Working with improving the language in laws and regulations is a never-ending story!

\section{Catharina Nyström Höög}

Catharina Nyström Höög is a professor of Swedish Language at Dalarna University, and guest professor at Uppsala University. In the year 2001, she participated in an evaluation of comprehensibility in texts written by public authorities, and since then, plain language has been a main interest in her research. In 2012, she co-authored "The public authorities hold the floor - on written texts from public authorities" with Hedda Söderlundh and Marie Sörlin

Too many texts might blur the view. On the mandate of public authorities, New Public Management and policy documents

Under the influence of New Public Management, the text repertoires of public authorities in Sweden have changed. Today, public authorities produce a number of different 
policy texts, such as policies for communication, and for behavior within the workplace. The mere existence of such texts, not explicitly directed at addressees outside the authority, challenges the role of plain language. Is it worthwhile to establish plain language strategies for those texts, or do they call for a different kind of action? Are the advocates of plain language obligated, according to the language act, to make policy texts "cultivated, simple and comprehensible"? In this article, I argue that it might be more important for the language cultivation within the public authorities to discuss the amount of texts produced, and why texts are produced. Too many texts may be a plain language problem in itself; they tend to blur the view.

\section{Aino Piehl}

Since 1998, Aino Piehl has worked as a special researcher and EU language advisor at The Institute for the Languages of Finland. She previously worked as a plain language adviser at the Institute's education unit. She has also published plain language handbooks and studies of the Finnish language in the EU. Aino Piehl served as the secretary of the work group that prepared a plain language programme for the Finnish Ministry of Education and Culture, as commissioned by the government.

\section{How does the government action programme help the authorities use intelligi- ble language?}

In 2013, the Finnish Ministry of Education and Culture appointed a work group to draw up an action programme for improving the authorities' use of language. The group's assignment was to propose methods and tools that would make the language of the authorities clear, understandable and matter-of-fact. The aim is for this requirement of the Administrative Procedures Act to be better implemented than before. The main theme of the work group's proposals was that clarity, intelligibility and matter-offactness in public administration language forms a cornerstone of a democratic society. Data for the project was gathered by collecting the experiences of the authorities, translators, language advisers and citizens.

The finished action programme was handed over to the Ministry of Education in 2014. The programme aims to shift the attention from single texts and formulations to the prerequisites and conditions for writing well. It is important that the authorities are aware of how much officials work with language, in writing or handling texts. The highest decision-making bodies, the managements of government agencies and each individual employee are jointly responsible for language quality, and that is why the programme contains measures for all these levels. Once the programme is completed it will also be necessary to market the recommendations of the programme, and inform the authorities of the benefits reaped from following the recommendations. 


\section{Marte Spets}

Marte Spets is a Communications Adviser for The Norwegian Public Roads Administration. She has been in charge of the plain language project, which won the Norwegian government's plain language prize in 2012. She is currently responsible for the plain language programme and has also worked with the texts rewritten by The Norwegian Public Roads Administration. She has worked at the Administration since 2009. Prior to that she worked at Aker Solutions and the aid organisation Plan.

\section{Plain language works! The Norwegian Public Roads Administration has the fig- ures to prove it}

The Norwegian Public Roads Administration has documented the effect of rewriting letters in clear and concise language, and training the personnel in doing so.

Every year, we at The Norwegian Public Roads Administration send out millions of letters to the Norwegian people. We realized that many of those receiving a letter simply did not understand its content, or what to do with the information provided in it. They needed help to understand, and contacted us. This resulted in us having an unnecessarily high number of cases where we responded to simple questions that the letters should have provided the answers for.

What happened once we rewrote 10 of our standard letters and retrained our personnel? And what happened to the views of our 6,500 employees in the course of the plain language project? Over a period of time, The Norwegian Public Roads Administration has carried out four separate evaluations that show plain language works.

\section{Marie Sörlin}

Marie Sörlin is a university lecturer in Scandinavian languages at the University of Umeå, where she teaches future language consultants. Her research interest is the communication of the authorities, not least the interaction between citizens and the authorities in social media. She is co-author of the book Myndigheterna har ordet ("The public authorities hold the floor") and has previously studied how well verdicts are understood, within the framework of Förtroendeutredningen (SOU 2008:106, "Increased trust in courts of law - strategies and suggestions").

\section{Lawyers and clients discussing verdicts - from interviews on perceived under- standing to "learning by interaction" as a method of studying intelligibility in texts}

Through their work, lawyers are privy to certain insights into how their clients understand and react to verdicts - insights that may prove useful in the plain language work with court texts. In my presentation I first described the results from a smaller 
interview-based study I conducted on this theme at the request of the so called Förtroendeutredningen (the Swedish Government Official Report on trust, SOU 2008:106, "Increased trust in courts of law - strategies and suggestions"). I then discussed the pros and cons of using interviews with lawyers to capture clients' understanding of court texts, and outlined a possible continuance study based on my results. In the article "Lawyers and clients discussing verdicts" I follow the same disposition, but look at the possible follow-up study in greater detail. Could the intelligibility of court texts

be investigated by analyzing the discussions between lawyer and client from a learning by interaction-perspective?

\section{Marjukka Turunen}

Marjukka Turunen works as a Program Leader for the Arkki project. Turunen has a long experience in renewing Kela's services.

\section{Towards a better service for customers - Developing the network services at the Social Insurance Institution in Finland (Kela)}

In Finnish Social Insurance Institution (Kela) all the operational IT-systems and network services will be renewed during the next ten years. The renewal project is part of Kela's strategy. What customers need, is the key to all the renewal projects because customers play an important role in developing the services.

In the Arkki project the focus is mainly on network services. Kela is investing in its network service channel because these services have been increasingly popular amongst customers. Through the internet services customers can e.g., check their personal data on benefits, apply for benefits and calculate the amounts of benefits. Students, families and unemployed are the biggest customer groups that use Kela's internet services. Customers have given Kela positive feedback for the internet services. 
